\title{
DESIGNDE SISTEMAS DE INFORMAÇÃO CENTRADO NO USUÁRIO E A ABORDAGEM DO SENSE-MAKING'
}

\author{
USER-CENTEREDINFORMATIONSYSTEMDESIGN \\ AND THESENSE-MAKINGAPPROACH
}

Edmeire Cristina PEREIRA²

\begin{abstract}
RESUMO
Esta pesquisa analisa alguns aspectos da interação ser humano-computador e da abordagem do Sense-Making (Dervin e outros), também reconhecida na literatura como "abordagem centrada no usuário" ou, ainda, "abordagem da percepção do usuário". Examina um site de uma empresa carioca (Rio de Janeiro, Brasil) do setor de farmácia, cosméticos e perfumaria, levando-se em consideração o lay-out das sucessivas telas com janelas, menus, botões, ícones e todos os componentes do sistema visíveis para o usuário. Como resultado das análises do conteúdo das páginas, da comunicação visual e de sua interatividade com os usuários potenciais, evidencia-se que o site não atende a todos os critérios de qualidade sugeridos pela literatura e, nem tampouco, a todas as diretrizes básicas para o design de sistemas de informação centrado no usuário, por Schneiderman e Bastien \& Scapin.
\end{abstract}

Palavras-chave: design de sistemas de informação centrado no usuário, interação ser humano-computador, abordagem sense-making.

\begin{abstract}
This article discusses the information from the user's perspective. Dervin and others have provided some insights into the nature of information and information seeking that can serve as a conceptual base for understanding how our thinking has to change in order to develop user-centered information services. An overview of Sense-Making Approach is presented. Also a designing of the user interface strategies for effective human-computer interaction, derived from Schneiderman and Bastien \& Scapin is presented. This study examined the site of
\end{abstract}

\footnotetext{
(1) Disciplina de Tecnologias da Informação (Parte 1 - Design de sistemas centrado no usuário), ministrada pela Profa. Dra. Laura Sánchez García, Curso de Mestrado Interinstitucional em Biblioteconomia e Ciência da Informação, PUC-Campinas (Convênio CAPES/MINTER), agosto/2000.

(2) Professora Assistente I, Departamento de Ciência e Gestão da Informação (DECIGI), Universidade Federal do Paraná (UFPR). Rua General Carneiro, 460, $7^{\circ}$ andar, Centro, 80060-150, Curitiba, PR. Mestre em Biblioteconomia e Ciência da Informação, PUC-Campinas.
} 
pharmaceutical/cosmetic company from Rio de Janeiro, Brazil. The results show that the pages contents, visual communication and effective human-computer interaction are not attending all the criteria suggested by literature-focused.

Key words: human information needs, information seeking from the user's perspective, sense-making approach, user-centered information system design.

\section{INTRODUÇÃO}

Para um entendimento mais próximo da problemática dos designs de sistemas de informação centrados no usuário, é interessante focalizar a questão dos paradigmas atuais em Ciência da Informação (CI), onde se discute, principalmente, a questão do acervo X (versus) acesso. Buckland (1991), Ferreira (1996), Saracevic (1996) e Tálamo (1996) têm contribuições nesse sentido, ou seja, sobre o conceito de Informação, sobre as novas percepções do usuário e sobre a origem, evolução e relações da Ciência da Informação com outras áreas interdisciplinares do conhecimento, tais como a Biblioteconomia, a Ciência da Computação, a Ciência Cognitiva, a Comunicação, etc.

Justamente pelo fato da CI ser uma área interdisciplinar, em constante evolução, seus problemas de pesquisa também acompanham essa mutação. Popper (1972) citado por Saracevic (1996, p. 41) já argumentava que “... não somos estudantes de assuntos, mas estudantes de problemas. E os problemas constituem os recortes de qualquer assunto ou disciplina”. Saracevic (1996, p. 47-8) dá um rol de "áreas de concentração de problemas para a pesquisa e a prática profissional - significando os enfoques intelectual e profissional, bem como as fronteiras da CI", a saber: a) efetividade; b) comunicação humana; c) conhecimento; d) registros do conhecimento; e) informação; f) necessidades de informação; g) usos da informação; h) contexto social; i) contexto institucional; j) contexto individual; 1) tecnologia da informação".

Pode-se constatar que todos são altamente complexos. Entretanto, fica evidente, também, que problemas ligados ao estudo de usuários sempre foram, e ainda são, direcionados para os sistemas, propriamente, e quase nada para os indivíduos, que são a essência dos serviços/sistemas atuais. Tálamo (1996, p. 14) afirma que "a administração da informação distancia-se da concepção tradicional de tratamento da informação porque centra-se nos processos de recepção, os quais consideram: o espaço de produção da informação docu-mentária, o tempo e os atores do consumo, o cotidiano (uso e práticas informacionais) e as especificidades dos dispositivos tecnológicos". Observa-se que essa distinção da autora, entre a administração da informação e o tratamento das informações, está em consonância com o enfoque contemporâneo da CI dado por Saracevic (1996, p. 47): “A Ciência da Informação é um campo dedicado às questões científicas e à prática profissional voltadas para os problemas da efetiva comunicação do conhecimento e de seus registros entre os seres humanos, no contexto social, institucional ou individual do uso e das necessidades de informação. No tratamento destas questões são consideradas de particular interesse as vantagens das modernas tecnologias informacionais".

É nesse panorama que se insere este artigo, cujo objetivo é discutir o planejamento e design de sistemas de informação a partir da perspectiva dos usuários da informação, ou seja, de uma visão holística do indivíduo, envolvendo aspectos cognitivos, psicológicos, sociais, demográficos, etc. Porém, é necessário saber que a área de estudos de usuários, desde o seu começo, em 1948, passou por várias fases, culminando atualmente, para os estudos de comportamento de busca e uso da informação. Segundo FERREIRA (1998), a literatura tem divergido em duas direções: a) abordagem tradicional, estudos direcionados sob a ótica do sistema de informação ou biblioteca (system-oriented approach ou traditional approach) e b) abordagem alternativa, isto é, direcionada sob a ótica do usuário (user-oriented approach ou alternative approach). São leituras indispensáveis neste caso: Kuhlthau (1991), Morris (1994), Taylor (1994), Ferreira (1997).

Sobre as abordagens alternativas, conhecidas também como abordagem centrada no usuário 
ou ainda, abordagem da percepção do usuário, estes novos estudos de comportamento de usuários se caracterizam por: 1) observar o ser humano como sendo construtivo e ativo; 2) considerar o indivíduo como sendo orientado situacionalmente; 3) visualizar holisticamente as experiências do indivíduo; 4) focalizar os aspectos cognitivos envolvidos; 5) analisar sistematicamente a individualidade das pessoas; 6) empregar maior orientação qualitativa (FERREIRA, 1997, p.8-9).

As bases dessa nova abordagem são: o processo de se buscar compreensão do que seja "necessidade de informação"deve ser analisado sob a perspectiva da individualidade do sujeito a ser pesquisado; a informação necessária e o tanto de esforço empreendido no seu acesso devem ser contextualizados na situação real onde ela emergiu; o uso da informação deve ser dado e determinado pelo próprio indivíduo (FERREIRA, 1997, p.8-9).

Com essas bases, portanto, "necessidade de informação (grifo do autor) não é um conceito subjetivo e relativo, o qual existe somente na mente de um indivíduo. Ao contrário, representa um conceito intersubjetivo (grifo meu) com significados, valores, objetivos, etc. passíveis de serem compartilhados. Um conceito que permite a identificação e generalização de padrões de comportamento de busca e uso de informação através do tempo e espaço sob a ótica do usuário" (FERREIRA, 1997, p.10).

Ainda, de acordo com Ferreira (1997, p.10), essa abordagem alternativa foi empregada primeiramente nas Ciências Sociais, posteriormente, na Comunicação e Informação. Especificamente, na área de CI, tal abordagem tem sido trabalhada em diferentes vertentes:

a) Abordagem de "Valor Agregado" de Robert Taylor - User-Values ou Value-Added (TAYLOR, 1986);

b) Abordagem do "Estado de Conhecimento Anômalo" de Belkin e Oddy e Brooks - Anomalous State-of-Knowledge (BELKIN e ODDY e BROOKS, 1982a; 1982b);

c) Abordagem do "Processo Construtivista" de Carol Kuhlthau - Constructive Process Approach (KUHLTHAU, 1993); d) Abordagem "Sense-Making" de Brenda Dervin (DERVIN, 1993).

De todas essas abordagens, Sense-Making, para FERREIRA (1997, p.17) oferece fundamentação básica, teórica, métodos e técnicas para se chegar ao design de sistemas de informação centrado realmente no usuário:

O modelo de Dervin permite a cada pessoa representar sua própria realidade. Na verdade, a teoria Sense-Making é um processo humano criativo de compreensão do mundo em um ponto particular no tempo e espaço, limitado pela capacidade psicológica e, ainda, dos acontecimentos presente, passado e futuro de cada indivíduo. Focaliza um ponto no tempo em que a informação é necessária.

Enquanto abordagem, o sense-making "consiste em pontuações de premissas teóricas e conceituais e outras tantas de metodologias relacionadas para avaliar como pacientes/ audiências/usuários/clientes/cidadãos percebem, compreendem, sentem suas interações com instituições, mídias, mensagens e situações, como usam a informação e outros recursos neste processo" (FERREIRA, 1997, p.11). (Usa-se escrever o nome dessa abordagem, desde 1994, com letras maiúsculas e com letras minúsculas para o fenômeno). Enquanto fenômeno, é definido: "como a atividade humana de observação, interpretação e compreensão do mundo exterior, inferindo-lhe sentidos lógicos, advindos do uso dos esquemas interiores" (FERREIRA, 1997, p.11).

Esta abordagem iniciou-se em 1972, nos EUA, com os estudos da Profa. Dra. Brenda Dervin, $P h D$ em Ciências da Comunicação da Ohio State University, na cidade de Columbus. Porém, somente em maio de 1983 foi publicado o documento contendo sua base filosófica, conceitual, teórica e metodológica, na International Communications Association Annual Meeting em Dallas, Texas, USA. De lá para cá, vários outros docu-mentos foram publicados sobre o tema, tanto nas áreas de comunicação, informação e biblioteconomia, educação, assistência social e psicologia. (...) O Sense-Making tem sido 
empregado em estudos desenvolvidos com amostras de 20 até 1 mil elementos, principalmente, teses de doutoramento, pesquisas acadêmicas, projetos encomendados, estudos empíricos, entre outros (FERREIRA, 1997, p.11-12).

A base conceitual do Sense-Making foi desenvolvida a partir das teorias de Bruner \& Piaget (cognição), Kuhn \& Habermas (constrangimento das ciências tradicionais e alternativas), Ascroft, Beltran \& Rolins (teoria crítica), Jackins \& Roger (terapia psicológica) e, principalmente, Carter, teórico da comunicação, o qual afirma que o homem cria idéias para transpor os "vazios" (gaps) que lhes são apresentados em decorrência da descontinuidade sempre presente na realidade. Os enunciados básicos desta abordagem, segundo Dervin (1983) citado por Ferreira (1997, p.12-13) são:

a) a realidade não é completa nem constante, ao contrário, é permeada de descontinuidades fundamentais e difusas, intituladas "vazios" (gaps). Assume-se que esta condição é generalizável porque as coisas na realidade não são conectadas e estão mudando constantemente;

b) a informação não é algo que exista independente e externamente ao ser humano, ao contrário, é um produto da observação humana;

c) desde que se considera a produção de infor-mação ser guiada internamente, então, o Sense-Making assume que toda informação é subjetiva;

d) busca e uso da informação são vistas como atividades construtivas, como criação pessoal do sentido individual do ser humano;

e) focaliza em como indivíduos usam as observações tanto de outras pessoas como as próprias para construir seus quadros da realidade e os usa para direcionar seu comportamento;

f) o comportamento dos indivíduos pode ser prognosticado com mais sucesso com a estruturação de um modelo que focalize mais suas situações de mudanças do que atributos denominados características de personalidades ou demográficas;

g) pesquisa por padrões, observando mais do que assumindo conexões entre situações e necessidades de informação, entre informação e uso; h) considera-se a existência de compreensões universais da realidade que permitem prognósticos e explicações melhores do que seria possível obter nas abordagens positivistas tradicionais (grifos do autor).

O Modelo de Darvin, modelo de três pontas, como ficou conhecido, foi construído sobre o trinômio situação-lacuna-uso (Dervin, 1992, p.69) (Figura 1).

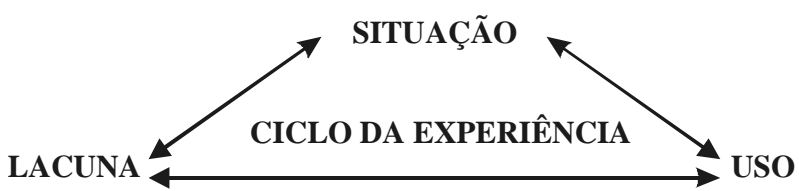

Figura 1: O Trinômio do Sense-Making.

- Situação: é o componente mais abrangente deste modelo. É o contexto temporal e espacial no qual surge a necessidade de informação, estabelece-se o período em que a busca e o uso da informação vai ocorrer e se chega (ou não) a compreensão do problema.

- Lacuna: pode ser definida como a situação problemática, um estado anômalo de conhecimento, um estado de incerteza (Krikelas, 1983), uma situação na qual um indivíduo está tentando chegar a compreensão de alguma coisa (Dervin, 1983).

- Uso: é o emprego dado ao conhecimento recém adquirido, traduzido na maioria dos estudos de usuários como a informação útil. (DERVIN, 1983), (FERREIRA, 1997, p.14-15).

Os atributos são: a) individualidade-usuários devem ser tratados como indivíduos e não como con-junto de atributos demográficos; b) situacionalidade - cada usuário se movimenta através de uma única realidade de tempo e espaço; c) utilidade da informação - diferentes indivíduos utilizam a informação de maneira própria e informação é o que auxilia a pessoa a compreender sua situação; d) padrões - analisando as características individuais de cada usuário, intenta-se chegar aos processos cognitivos comuns à maioria (FERREIRA, 1997, p.16).

Segundo Ferreira (1997, p.16-17), Dervin desenvolveu uma técnica para operacionalizar seu 
modelo através da qual os usuários constróem um timeline (doravante traduzido para "cronograma"). Esse cronograma intenta conduzir o usuário à reconstrução de um quadro referencial, observando o local e o tempo dos acontecimentos. Alguns autores intitulam esse quadro de "matriz cognição x ação". Nele é descrita a seqüência de acontecimentos (intitulado eventos), que ocorrem em dada situação. Essas situações são operacionalizadas como o contexto ou cenários no qual o usuário necessita de informação. Os eventos são operacionalizados como cenas momentâneas da situação do usuário, similares às imagens congeladas de um filme. Eles são etapas no cronograma. As lacunas são operacionalizadas como questões ou dúvidas que os usuários concebem em um evento particular. Usos são operacionalizados como o modo com que as respostas a essas questões auxiliam, ou não, a solução das necessidades de informação, em um dado evento de uma situação.

\section{MINI-PROJETO DE AMBIENTE DE INTERFACE}

O estudo de caso a seguir refere-se à uma empresa do setor de farmácia, cosméticos e perfumaria, com sede no Rio de Janeiro. Até o ano de 1994, essa empresa funcionava do mesmo jeito desde a época de sua fundação, em 1870. Havia se isolado de sua clientela e não conseguia falar a linguagem da globalização. Paduan (2000, p.68-69), em seu artigo sobre esta empresa, registra a seguinte situação:

(...) A empresa não tinha um único aparelho de fax e as quatro ou cinco linhas de telefone instaladas na sede da empresa não eram interligadas em ramais. Computadores, ali, nem a passeio. A linha de produção era manual e o departamento comercial seguia uma rotina tão anacrônica que parece inacreditável. Vendedores tinham de preencher as faturas a mão, mandar os pedidos pelo Correio e torcer para a carta não se extraviar no meio do caminho. A empresa mudou de dono em 1994 e, de lá para cá, saiu da era do selo e do envelope e mergulhou no mundo digital. Foi o que garantiu sua sobrevivência.
Como resultado dessa metamorfose da empresa, hoje, o que está acontecendo por lá é que "os representantes comerciais da companhia saem a campo carregando palmtops. Os aparelhos são utilizados para anotar os pedidos, que seguem para a fábrica via Internet minutos depois de confirmados. A empresa colocará na rede um sistema de comércio eletrônico atualizadíssimo. Os clientes poderão consultar os estoques, verificar detalhes dos pedidos feitos anteriormente e fazer novos pedidos."

Essa história verídica "ilustra como poucas o impacto positivo que um sistema ágil de troca de informações provoca sobre uma companhia" (PADUAN, 2000). Basta pensar que hoje há autores, como Castells (1999), que se reportam às tecnologias da informação (TI) como uma "Revolução", ou seja, uma "transformação de nossa cultura material" pelos mecanismos de um novo paradigma tecnológico que se organiza em torno da tecnologia da informação. Esse autor, inclui, entre as TI, o conjunto convergente de tecnologias em microeletrônica, computação (software e hardware), telecomunicações/radiodifusão e optoeletrônica. Além disso tudo, inclui também, a Engenharia Genética e seu crescente conjunto de desenvolvimentos e aplicações.

Em recente mesa-redonda com os professores do Geórgia Institute of Technology, o Geórgia Tech, o jornalista Abramson (1999), da equipe de jornalistas da revista CIO, entrevistou um grupo de especialistas sobre o impacto da revolução da informação, muitas vezes não percebido, da TI em vários setores em escala mundial. A resposta de um deles, Papp, é a de que “(...) esse é um dos problemas reais da Era da Informação. Ou seja, o potencial para atuar em escala mundial versus o ressentimento das pessoas que vêem seus hábitos ameaçados." Outro entrevistado,Tjaden, disse que: "A revolução da informação força a empresa a mudar da produção em massa para a personalização em massa. A necessidade de um cliente do Irã é diferente da necessidade de um do Sudão. Na revolução da informação, o papel de uma empresa bem-sucedida é descobrir como satisfazer essas diferentes necessidades". 
Do resultado de seu planejamento estratégico da informação, foi identificada a necessidade de elaboração de um Executive Information System (EIS) para a empresa, dentre outros itens. Nesse plano, foram relacionados os seguintes objetos estratégicos sugeridos por Furlan (1994): Missão da empresa; Objetivos de negócio; Fatores críticos de sucesso do negócio; Necessidades de informação para suportar os fatores críticos de sucesso do negócio: a) Produção; b) Marketing; c) Logística; d) Origem da matéria-prima; e) Recursos Humanos; f) Informática.

Apesar da abrangência do EIS, foi decidido prioritariamente o desenvolvimento do módulo para a função de Informática, por tratar-se de uma área de contribuição crítica para o desempenho do negócio.

Desse planejamento estratégico, os maiores problemas, do ponto de vista da informática na empresa, foram: a) o isolamento da clientela e dos fornecedores, por causa da falta de uma comunicação mais eficiente (via Internet, por exemplo); b) a ausência de comunicação em tempo real entre as fábricas, os depósitos e os escritórios; c) ausência da empresa na $W e b$, porque não tinham um site para se comunicar com os clientes e fornecedores.

A partir desse diagnóstico, a empresa estruturou um prognóstico com as seguintes estratégias: a) proposta da rede de computadores: uma rede Wan conectando as Lans das filiais com a matriz e as empresas fornecedoras de matéria-prima possibilitando uma comunicação eficiente e rápida para o gerenciamento da empresa; b) proposta de criação de site na Internet, para efetivar a comunicação em rede com os clientes e fornecedores; c) colocar na rede Internet um sistema de e-commerce (comércio eletrônico) atualizadíssimo. Os clientes poderão consultar os estoques, verificar detalhes dos pedidos feitos anteriormente e fazer novos pedidos.

Com essas ações, a empresa compatibilizou preço e qualidade técnica de seus produtos e processos; com a utilização da rede Internet e o compartilhamento das informações, agilizou o seu fluxo de informações e processos.

Portanto, esta pesquisa teve por objetivos: a) Geral: Analisar o site da empresa e observar a funcionalidade de suas telas (home pages), com vistas a ver se a empresa está ou não mais interativa com seus clientes, fornecedores e demais pessoas da comunidade; b) Específicos: Analisar o conteúdo das páginas; Analisar a comunicação visual das páginas, no tocante à cor, tamanho das telas, figuras, ícones, etc.; Analisar os aspectos da interatividade com o usuário potencial.

\section{A Interação Ser Humano-Computador (IHC)}

Consultando o trabalho de Sánchez García (2000), foram extraídos os seguintes pontos que são de interesse à problemática do design de sistemas de informação, no que diz respeito à interação ser humano-computador:

a principal razão pela qual se investe em pesquisa na indústria na área de IHC é a busca do aumento da eficiência e a produtividade dos funcionários e, conseqüentemente, de um maior ganho financeiro (p.1).

Durante a explosão da tecnologia nos anos 70, a noção de interface-usuário, identificada à de interface homem-máquina, começou a se tornar uma preocupação dos projetistas de softwares (p.2).

Em paralelo à evolução das interfaces, evoluíram também, os editores de texto (p.4).

o ponto é sempre como projetar sistemas computacionais para que eles tenham impacto positivo nas organizações". E, referindo-se à tarefa do projetista: "A tarefa do projetista consiste, assim, na identificação de breakdowns e na preparação das intervenções que acomodem as atividades de forma a evitá-los sempre que possível e a conviver com os que sempre ocorrem. "A esse respeito, existem três conceitos envolvidos no design de interfaces. São eles:1) Readiness-to-hand, ou seja, a transparência do sistema ao alcance de suas mãos. Ex.: direção de automóvel (automática); 2) Breakdown, 
isto é, erros, cortes, impasses no sistema. Eles podem ser: computacionais (mensagem que não pode ser enviada, por exemplo); de domínio (quebra de compromisso assumido e modelado por um sistema de controle de tarefas, por exemplo); 3) Blindness, istoé, quando a tecnologia se sobrepõe a práticas eficientes. Por exemplo: sistema de acesso on-line a bibliotecas. Assim: a função de "achar um livro a partir de informação precisa." OK; já, a de "achar leituras relevantes para o meu objetivo...? (p. 8).

Quanto às diretrizes, regras práticas e listas de verificação para a concepção de designs, são assim resumidas:

Diretrizes - são princípios derivados da experiência de pesquisadores e projetistas (heurísticas) ao longo do tempo, que devem ser verificados para que uma interface seja minimamente adequada. Regras Práticas - são instruções que podem ser obedecidas sem necessidade de interpretação e aplicação ao contexto pelo designer. Exemplo de uma regra prática é: "Nos Estados Unidos, os campos para data devem ser oferecidos na forma mm-dd-yy". Listas de Verificação (CHECKLISTS) - são conjuntos de itens cuja presença ou ausência atestam o grau de qualidade da interface (p.15).

Schneiderman (1992) citado por Sánchez García (2000) elencou 9 diretrizes básicas para o design de interfaces. São elas: 1) Consistência; 2) Atalhos para usuários experientes; 3) Feedback informativo; 4) Consideração do todo das tarefas; 5) Bom tratamento de erros; 6) Volta atrás (undo); 7) Papel de iniciador de ações para o usuário; 8) Minimização da necessidade de memorização; 9) Uso de técnicas para prender a atenção do usuário (p.17).

Bastien \& Scapin (1993) citados por Sánchez García (2000), por sua vez, elencaram 18 critérios de qualidade que pautam a lista de verificação do Labutil. Esses critérios são: 1) Presteza; 2) Agrupamento espacial por significado; 3) Agrupamento visual por significado; 4) Feedback; 5) Legibilidade; 6) Concisão; 7) Ações mínimas; 8) Densidade informacional; 9) Ações explícitas; 10) Controle do sistema pelo usuário; 11) Flexibilidade; 12) Experiência do usuário; 13) Proteção contra erros; 14) Mensagens de erro; 15) Correção de erros; 16) Consistência; 17) Códigos naturais; 18) Compatibilidade (p.19-26).

Com relação aos aspectos de modelos mentais ou cognitivos no uso de sistemas computacionais, os dois princípios fundamentais do design são: Proporcione um bom modelo conceitual; Torne as coisas visíveis (p.50).

A imagem do sistema deve ser explícita, inteligível e consistente (p.54).

Como a Interação Humano-Computador envolve muitas áreas do conhecimento, dentre as quais: Ciência da Computação; Psicologia Cognitiva; Design; Ergonomia e estudo de fatores humanos; Psicologia Social e Organizacional; Lógica; Lingüística; Inteligência Artificial; Filosofia, Sociologia e Antropologia; Engenharia; não existe uma metodologia capaz de dar conta de todas as situações possíveis no design de interfaces. (...) No entanto, esforços têm sido feitos no sentido de situar, de maneira geral, o projeto de interfaces no processo de projeto de software, assim como para propor modificações nessa dinâmica (p.90).

Design Conceitual se preocupa com as questões relativas ao que é requerido do sistema, o que ele deve fazer, que dados são necessários, o que os usuários vão precisar saber...; Design Físico ou Formal se preocupa com a forma na qual estas coisas podem ser alcançadas (p.95). 
Finalmente, sobre o Design de Ambientes para a World Wide Web, pode-se dizer que herdou a maioria dos requisitos e pressupostos do projeto de ambientes de hipermídia e de interfacesusuário, em geral. Nesse caso, nos ambientes de hipermídia, o design tem de responder às questões: Onde eu estou? O que eu já vi? O que mais há para ver? Como posso fazer para vê-lo?" (Preece, 1994 citado por SÁNCHEZ GARCÍA, 2000)

Portanto, o design de home-pages deve levar em conta: seu conteúdo, o design visual, estruturação (de forma hierárquica, em árvores balanceadas), um modelo conceitual (p. 98)

Em termos de comunicação visual, alguns requisitos têm de ser observados:

Cor: pede-se cautela no seu uso. A sugestão geral para o uso de cor é a de se usar apenas com significado, para não confundir e/ou distrair o usuário.

Tamanho da Tela: a maioria dos computadores de mesa disponíveis têm um tamanho de tela de $640 \mathrm{X} 480$ ou $800 X 600$ pixels. É convencional supor que os browsers oferecem uma página de pelo menos 472 pixels de largura, portanto, bons designers devem se ater a esse tamanho e não a mais.

Figuras: pede-se cautela. Não podem comprometer o acesso à informação textual.

Restrições Lógicas: devem ser consideradas na concepção de menus gráficos.

Uso de Figuras como Menus: falta de indicação clara sobre quais partes da figura que determinam o acesso a diferentes documentos.

Ícones: são utilizados, nas páginas Web, com dois objetivos distintos: a) para acompanhar instruções ou rótulos funcionais; b) como ícones de uma interface, ou seja, representando uma função (ou, em certos casos, uma informação) disponível. O uso de ícones, assim como, o uso de cor e de recursos gráficos, deve ser inteligente; não devem ser criados aleatoriamente e devem ser o menos arbitrários possível (p.98).

\section{MATERIALE MÉTODOS}

Para análise do site da empresa do setor de farmácia, cosméticos e perfumaria, foram elaborados os Quadros 1 e 2 de recomendações de diretrizes e critérios de qualidade e Tabelas 1 e 2 para pontuação (positiva ou negativa) dessas diretrizes e critérios aplicados à empresa analisada. Estes quadros e tabelas constituíram o instrumental teórico-metodológico para coleta de dados deste estudo.

Os procedimentos adotados foram: Estudo sobre IHC para ver quais são as recomendações sobre ambientes de interface centrados no usuário; Captura de todas as telas do site da empresa; Construção de uma ou mais tabelas para pontuar as observações encontradas no site da empresa, mediante as 9 diretrizes básicas de Schneiderman (1992) e os 18 critérios de qualidade que pautam a lista de verificação de Labutil, elencadas por Bastien \& Scapin (1993) citados por (SÁNCHEZ GARCÍA, 2000).

A seguir, os resultados de análise dessas recomendações aplicadas ao site da empresa analisada (Tabela 1, Anexo 1).

\section{RESULTADOSEDISCUSSÃO}

Assim, percebe-se que o site da empresa analisada está, de certa forma, equilibrado com o que preconiza a literatura estudada, ou seja, ele tem uma interface razoavelmente amigável com seus usuários e suas telas são funcionais.

$\mathrm{O}$ site segue a maioria das diretrizes propostas por Schneiderman (1992), porém, não atende a todos os critérios de qualidade de Bastien \& Scapin (1993) (SÁNCHEZ GARCÍA, 2000) (Anexos 2 e 3). 
Quanto ao conteúdo das páginas é de extrema simplicidade e pertinência, porque reúne em 10 tópicos todas as informações úteis e curiosas da empresa para os usuários. Pelos tópicos abordados e pela redação clean, observa-se que se trata de uma empresa "politicamente correta".

Sobre os aspectos da comunicação visual das páginas, observou-se: 1) Cor - A cor vermelha é usada somente para tópicos significativos do site. Com isso, não provoca uma poluição visual no usuário e nem o confunde, nem o distrai; 2) Tamanho das Telas - Já na primeira página do site existe o alerta da Winco: "Este site é melhor visualizado em 800 x 600, com o Internet Explorer ou Netscape Navigator 4 ou superior." A convenção recomenda que os browsers ofereçam uma página de, pelo menos, 472 pixels de largura e não mais; 3) Figuras - São em número de 14 , não comprometem o acesso à informação textual e são balanceadas e alusivas ao texto que as acompanha; e 4) Ícones - São equilibrados, não são aleatórios e nem arbitrários; portanto, são inteligentes.

\section{CONCLUSÃO}

Os resultados obtidos neste estudo nos permitem destacar que: a) O site da empresa analisada é simples e funcional, porém, não atende a todos os critérios de qualidade sugeridos pelos autores da área de IHC e nem todas as diretrizes básicas para o design de sistemas centrado no usuário. No entanto, para os requisitos de cor, tamanho das telas e ícones é satisfatório;

b) O conteúdo das páginas do site é pontual e registra o que há de mais importante. Um navegador ocasional da Internet, que visitasse suas páginas, poderia saber a respeito dessa empresa genuinamente brasileira, da área farmacêutica e cosmética. É muito interessante a parte de curiosidades da empresa, onde ficamos sabendo de momentos importantes da história da Companhia, momentos estes que já se encontram entrelaçados com a própria história das pesquisas farmacêuticas no Brasil;

c) Em termos de interatividade com o usuário, a pesquisa detectou que o site atende a maior parte das diretrizes básicas da literatura. No entanto, ele não cobre todos os critérios de qualidade, também, sugeridos pela área de IHC.

Enfim, apesar do sistema ser pouco complexo, a sua análise foi uma experiência interessante, pela mudança de uma visão ingênua para uma visão crítica, no tocante ao aspecto da interação ser humano-computador, em suas diversas nuances.

Tabela 1. Pontuação para o Site, mediante as 9 Diretrizes Básicas de Schneiderman (1992) citado por Sánchez García (2000).

\begin{tabular}{|c|c|c|c|}
\hline Pontuação & Positiva $(+)$ & Negativa (-) & Total \\
\hline 1. Consistência & + & & + \\
\hline 2. Atalhos para usuários experientes & & - & - \\
\hline 3. Feedback informativo & & - & - \\
\hline 4. Consideração do todo das tarefas & + & & + \\
\hline 5. Bom tratamento de erros & + & & + \\
\hline 6. Volta atrás (undo) & + & & + \\
\hline 7. Papel de iniciador de ações para o usuário & & - & - \\
\hline 8. Minimização da necessidade de memorização & + & & + \\
\hline 9. Uso de técnicas p/ prender a atenção do usuário & + & & + \\
\hline Total & 6 & 3 & 9 \\
\hline
\end{tabular}

Fonte: Pesquisa de Campo. 


\section{REFERÊNCIAS}

ABRAMSON, G. A TI muda tudo. HSM Management, 17,p.102-106, nov./dez. 1999.

BUCKLAND, M.K. Information as thing. Journal of the American Society for Information Science, v.42, n.5, p.351-360, 1991.

CASTELLS, M.A. A revolução da tecnologia da informação. In: CASTELLS, M.A. A sociedade em rede. 2.ed. São Paulo: Paz e Terra, 1999. v.1.

DERVIN, B. Communication gaps and inequities: moving toward a reconceptualization. In: DERVIN, B.; VOIGT, M. Progress in Communication Sciences. Norwood, N.J.: Ablex, 1980. v.2, p.73-112.

DERVIN, B. An overview of Sense-Making research: concepts, methods and results to date. In: International Communications Association Annual Meeting. Dallas, May.

DERVIN, B. From the mind's eye of the user: the sense-making qualitative-quantitative methodology. In: GLAZIER, J.D.J.D.; POWELL, R.R. Quatitative Research in Information Management. Englewood, CO: Libraries Unlimited, 1992.p.61-84.

DERVIN, B. An overview of Sense-Making research: concepts, methods and results to date. [on line] In: INTERNATIONAL COMMUNICATIONS ASSOCIATION ANNUAL MEETING, Dallas/TX, may 1993. Available from Internet <.URL: <http:// www.eca.usp.br/eca/prof/sueli/sense - 1983. htm >.

FERREIRA, S.M.S.P. Novos paradigmas da informação e novas percepções do usuário. Ciência da Informação, Brasília, v.25, n.2, p.217-223, 1996.

FERREIRA, S.M.S.P. Estudo de necessidades de informação: dos paradigmas tradicionais à aborda- gem Sense-Making. Porto Alegre: ABEBD, 1997. 21p. (Documentos ABEBD, 2).

FERREIRA, S.M.S.P. Sistema de informação centrado no usuário: programa e material para leitura. In: CURSO DE ESPECIALIZAÇÃO EM GESTÃO DE BIBLIOTECAS-MÓDULOI-USUÁRIOS. Curitiba: UFPR, 1998. 5p. (Mimeografado).

FURLAN, J.D.; IVO, I.M.; AMARAL, F.P. Sistemas de informação executiva - EIS - Executive Information Systems. São Paulo: Makron Books, 1994. p.131-152.

KRIKELAS, J. Information-seeking behavior: patterns and concepts. Drexel Library Quarterly, v.19, n.2, p.5-20, 1983.

KUHLTHAU, C. Inside the search process: information seeking from the user's perspective. Journal of the American Society for Information Science, v.42, n.5, p.361-371, 1991 .

MORRIS, R.T. Toward a user-centered information service. Journal of the American Society for Information Science, v.45, n.1, p.20-30, 1994.

PADUAN, R. High tech aos 130 anos. Veja Vida Digital, v.33, n.16, p.68-69, 2000.

SÁNCHEZ GARCÍA, L. Design de sistemas centrado no usuário. Curitiba: UFPR, 2000. 100 p. (Apostila).

SARACEVIC, T. Ciência da informação: origem, evolução e relações. Perspectivas em Ciência da Informação, Belo Horizonte, v.1, n.1, p.41-62, 1996.

TÁLAMO, M.F.G.M. Informação: organização e comunicação. In: SEMINÁRIO DE ESTUDOS DE INFORMAÇÃO, 1., Niterói, 1996. Anais... Niterói: Universidade Federal Fluminense, 1996. p.11-14.

TAYLOR, R. The Value-added information system. Washington DC: Ablex, 1994. 


\section{ANEXO 1}

Pontuação para o Site, mediante os Critérios de Qualidade que pautam a Lista de Verificação do Labutil Bastien \& Scapin, 1993 citados por SÁNCHES GARCÍA (2000).

\begin{tabular}{|c|c|c|c|c|}
\hline Critérios & Tópicos de Verificação do Labutil (Bastien \& Scapin, 1993) & $(+)$ & $(-)$ & Total \\
\hline 1. Presteza & $\begin{array}{l}\text { Verifique se o sistema informa e conduz o usuário durante a } \\
\text { interação. }\end{array}$ & + & & + \\
\hline $\begin{array}{l}\text { 2. Agrupamento espacial por } \\
\text { significado }\end{array}$ & $\begin{array}{l}\text { Verifique se a distribuição espacial dos itens traduz as relações de } \\
\text { significado entre as informações e funções. }\end{array}$ & + & & + \\
\hline $\begin{array}{l}\text { 3. Agrupamento visual por } \\
\text { significado }\end{array}$ & $\begin{array}{l}\text { Verifique se as características visuais dos itens são exploradas } \\
\text { como meio de transmitir associações e diferenças. }\end{array}$ & + & & + \\
\hline 4. Feedback & $\begin{array}{l}\text { Avalie a qualidade do feedback (retorno) imediato às ações do } \\
\text { usuário. }\end{array}$ & + & & + \\
\hline 5. Legibilidade & $\begin{array}{l}\text { Verifique a legibilidade das informações apresentadas nas telas do } \\
\text { sistema. }\end{array}$ & + & & + \\
\hline 6. Concisão & $\begin{array}{l}\text { Verifique o tamanho dos códigos e termos apresentados, exigidos } \\
\text { e introduzidos no sistema. }\end{array}$ & & - & - \\
\hline 7. Ações Mínimas & $\begin{array}{l}\text { Verifique a granularidade das ações e a extensão dos diálogos } \\
\text { estabelecidos para a realização dos objetivos do usuário. }\end{array}$ & & - & - \\
\hline 8. Densidade Informacional & $\begin{array}{l}\text { Avalie a densidade informacional das telas apresentadas pelo } \\
\text { sistema. }\end{array}$ & + & & + \\
\hline 9. Ações explícitas & $\begin{array}{l}\text { Verifique se é o usuário quem comanda as ações do sistema. Avalie } \\
\text { as possibilidades de o usuário controlar o encadeamento e a } \\
\text { realização de ações. }\end{array}$ & & - & - \\
\hline $\begin{array}{l}\text { 10. Controle do sistema pelo } \\
\text { usuário }\end{array}$ & $\begin{array}{l}\text { Verifique se é o usuário quem comanda as ações do sistema. Avalie } \\
\text { as possibilidades de o usuário controlar o encadeamento e a } \\
\text { realização de ações. }\end{array}$ & & - & - \\
\hline 11. Flexibilidade & $\begin{array}{l}\text { Verifique se o sistema permite personalizar as apresentações e os } \\
\text { diálogos. }\end{array}$ & & - & - \\
\hline 12. Experiência do usuário & $\begin{array}{l}\text { Avalie se os usuários com diferentes níveis de experiência têm iguais } \\
\text { possibilidades de obter sucesso em seus objetivos. }\end{array}$ & & - & - \\
\hline 13. Proteção contra erros & $\begin{array}{l}\text { Verifique se o sistema oferece as oportunidades para o usuário } \\
\text { prevenir eventuais erros. }\end{array}$ & & - & - \\
\hline 14. Mensagens de erro & $\begin{array}{l}\text { Avalie a qualidade das mensagens de erro enviadas aos usuários em } \\
\text { dificuldades. }\end{array}$ & & - & - \\
\hline 15. Correção de erros & $\begin{array}{l}\text { Verifique as facilidades oferecidas para que o usuário possa corrigir } \\
\text { os erros cometidos. }\end{array}$ & & - & - \\
\hline 16. Consistência & $\begin{array}{l}\text { Avalie se é mantida uma coerência no projeto de códigos, telas e } \\
\text { diálogos com o usuário. }\end{array}$ & + & & + \\
\hline 17. Códigos Naturais & $\begin{array}{l}\text { Avalie se os códigos e as denominações são naturais e significativos } \\
\text { para o usuário do sistema. }\end{array}$ & + & & + \\
\hline 18. Compatibilidade & $\begin{array}{l}\text { Verifique a compatibilidade do sistema com as expectativas e } \\
\text { necessidades do usuário na execução de sua tarefa. }\end{array}$ & + & & + \\
\hline Total & & 9 & 9 & 18 \\
\hline
\end{tabular}

Fonte: Pesquisa de Campo. 


\section{ANEXO 2}

Diretrizes Básicas para o Design de Interfaces segundo Schneiderman (1992) citado por Sánchez García (2000).

\begin{tabular}{ll}
\hline Diretrizes & Autoria \\
\hline
\end{tabular}

\section{Consistência}

2. Atalhos para usuários experientes

3. Feedback informativo

4. Consideração do todo das tarefas

5. Bom tratamento de erros

6. Volta atrás (undo)

7. Papel de iniciador de ações para usuário

8. Minimização da necessidade de memorização

9. Uso de técnicas para prender a atenção do usuário
Schneiderman

Seqüências consistentes de ações;

Terminologia idêntica para mensagens com o mesmo objetivo; Comandos agindo de forma consistente.

Abreviações; Teclas especiais; Macros; Respostas sintéticas.

Em ações atômicas e freqüentes, a necessidade é menor;

Em ações maiores e mais raras, é maior;

Representação visual dos objetos facilita este ponto.

Organização e exibição de seqüências de ações devem ser claras (Ex.: delimitação de bloco e seleção de operação sobre ele).

Minimizar probabilidade de ocorrência; Fornecer fácil correção e recuperação.

Possibilidade de voltar atrás encoraja o uso e a exploração do ambiente; Unidade deve ser cuidadosamente selecionada (dado, ação ou grupo de ações), pois traz vantagens e desvantagens associada.

Duas unidades de informação são perceptíveis simultaneamente; Acesso online à sintaxe de comando e outras informações necessárias.

Intensidade: dois níveis; Destaque de informação: usar molduras; Tamanho: até 4 distintos; Fontes: até três; Cores: até quatro; Mudanças visuais para feedback; Alarme para ações perigosas ou proibidas (mais inibição). Uso indevido ou exagerado tem resultado contrário ao esperado.

Fonte: Sánchez García (2000). 


\section{ANEXO 3}

Critérios de Qualidade que pautam a Lista de Verificação do Labutil (Bastein \& Scapin (1993) citado por Sáchez Garcia (2000).

Critérios Autoria $\quad$ Lista de Verificação do Labutil (Bastien \& Scapin, 1993)

1. Presteza

2. Agrupamento espacial por significado

3. Agrupamento visual por significado

4. Feedback

5. Legibilidade

6. Concisão

7. Ações Mínimas

8. Densidade Informacional

9. Ações Explícitas

10. Controle do sistema pelo usuário

11. Flexibilidade

12. Experiência do usuário

13. Proteção contra erros

14. Mensagens de erro

15. Correção de erros

16. Consistência

17. Códigos Naturais

18. Compatibilidade
Verifique se o sistema informa e conduz o usuário durante a interação.

Verifique se a distribuição espacial dos itens traduz as relações de significado entre as informações e funções.

Verifique se as características visuais dos itens são exploradas como meio de transmitir associações e diferenças.

Avalie a qualidade do feedback (retorno) imediato às ações do usuário.

Verifique a legibilidade das informações apresentadas nas telas do sistema.

Verifique o tamanho dos códigos e termos apresentados, exigidos e introduzidos no sistema.

Verifique a granularidade das ações e a extensão dos diálogos estabelecidos para a realização dos objetivos do usuário.

Avalie a densidade informacional das telas apresentadas pelo sistema.

Verifique se é o usuário quem comanda as ações do sistema. Avalie as possibilidades de o usuário controlar o encadeamento e a realização de ações.

Verifique se é o usuário quem comanda as ações do sistema. Avalie as possibilidades de o usuário controlar o encadeamento e a realização de ações.

Verifique se o sistema permite personalizar as apresentações e os diálogos.

Avalie se os usuários com diferentes níveis de experiência têm iguais possibilidades de obter sucesso em seus objetivos.

Verifique se o sistema oferece as oportunidades para o usuário prevenir eventuais erros.

Avalie a qualidade das mensagens de erro enviadas aos usuários em dificuldades.

Verifique as facilidades oferecidas para que o usuário possa corrigir os erros cometidos.

Avalie se é mantida uma coerência no projeto de códigos, telas e diálogos com o usuário.

Avalie se os códigos e as denominações são naturais e significativos para o usuário do sistema.

Verifique a compatibilidade do sistema com as expectativas e necessidades do usuário na execução de sua tarefa.

Fonte: Sánchez García (2000). 
